\title{
Publisher Correction: Distinct synchronization, cortical coupling and behavioral function of two basal forebrain cholinergic neuron types
}

Tamás Laszlovszky, Dániel Schlingloff, Panna Hegedüs, Tamás F. Freund, Attila Gulyás, Adam Kepecs and Balázs Hangya (D) Correction to: Nature Neuroscience https://doi.org/10.1038/s41593-020-0648-0, published online 22 June 2020.

In the version of this article initially published, errors appeared in Fig. 2d,j. In Fig. 2d, the axes of the bottom graph should appear in front of the data; in Fig. 2j, the cell count should start at 1 rather than at 0 . The errors have been corrected in the PDF and HTML versions of this article.
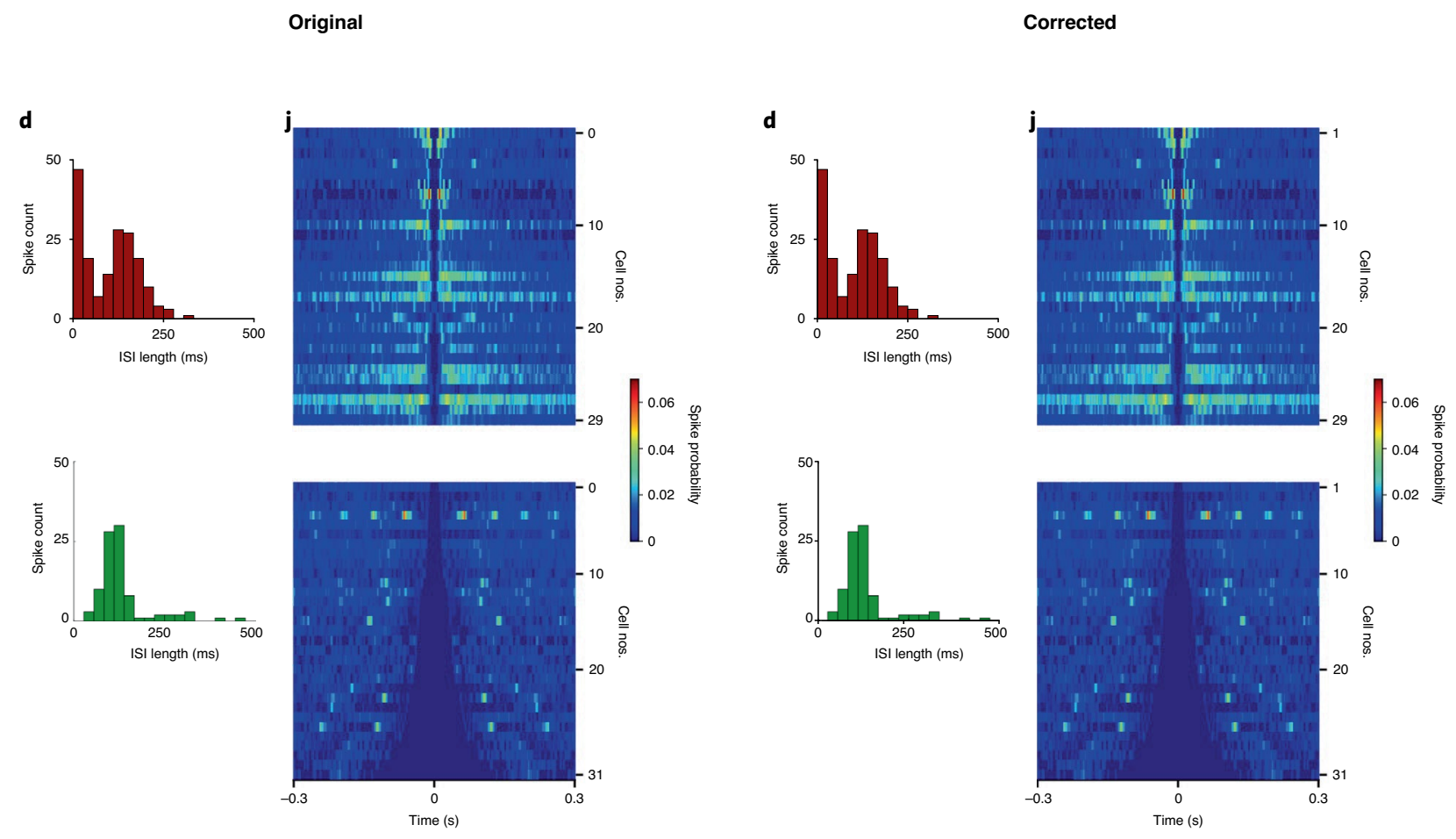

Fig. 2 | Original and Corrected.

Published online: 14 August 2020

https://doi.org/10.1038/s41593-020-0702-y

(c) The Author(s), under exclusive licence to Springer Nature America, Inc. 2020 